\title{
The impact of hypsarrhythmia on infantile spasms treatment response: Observational cohort study from the National Infantile Spasms Consortium
}

\author{
'Scott T. Demarest (D), ${ }^{2}$ Renée A. Shellhaas $10,{ }^{3}$ William D. Gaillard, ${ }^{4}$ Cynthia Keator, \\ ${ }^{5}$ Katherine C. Nickels, ${ }^{6}$ Shaun A. Hussain, ${ }^{7}$ Tobias Loddenkemper, ${ }^{8}$ Anup D. Patel, \\ ${ }^{9}$ Russell P. Saneto, ${ }^{5}$ Elaine Wirrell, ${ }^{7}$ Iván Sánchez Fernández, ${ }^{10}$ Catherine J. Chu, \\ 1 'Zachary Grinspan, ${ }^{12}$ Courtney J. Wusthoff, ${ }^{2}$ Sucheta Joshi, ${ }^{13}$ Ismail S. Mohamed, \\ ${ }^{14}$ Carl E. Stafstrom, ${ }^{15}$ Cynthia V. Stack, ${ }^{16}$ Elissa Yozawitz, ${ }^{17}$ Judith S. Bluvstein, ${ }^{18}$ Rani K. Singh, \\ 'Kelly G. Knupp, and the Pediatric Epilepsy Research Consortium
}

Epilepsia, 58(12):2098-2103, 2017

doi: 10.1111/epi.13937

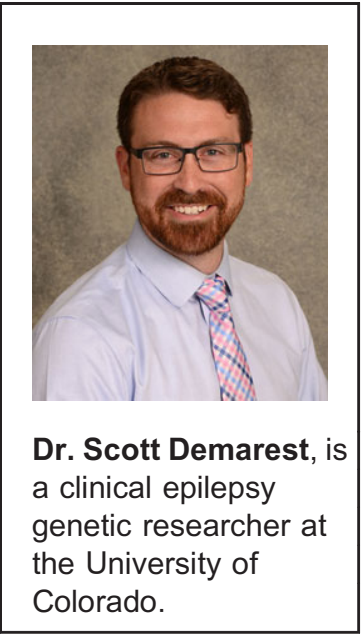

\section{SUMMARY}

Objective: The multicenter National Infantile Spasms Consortium prospective cohort was used to compare outcomes and phenotypic features of patients with infantile spasms with and without hypsarrhythmia.

Methods: Patients aged 2 months to 2 years were enrolled prospectively with newonset infantile spasms. Treatment choice and categorization of hypsarrhythmia were determined clinically at each site. Response to therapy was defined as resolution of clinical spasms (and hypsarrhythmia if present) without relapse 3 months after initiation.

Results: Eighty-two percent of patients had hypsarrhythmia, but this was not associated with gender, mean age, preexisting developmental delay or epilepsy, etiology, or response to first-line therapy. Infants with hypsarrhythmia were more likely to receive standard treatment (adrenocorticotropic hormone, prednisolone, or vigabatrin [odds ratio (OR) 2.6, 95\% confidence interval (CI) 1.4-4.7] and preexisting epilepsy reduced the likelihood of standard treatment (OR 3.2, 95\% CI I.9-5.4). Hypsarrhythmia was not a determinant of response to treatment. A logistic regression model demonstrated that later age of onset (OR I.09 per month, 95\% CI I.03-I.I5) and absence of preexisting epilepsy (OR I.7, 95\% CI I.06-2.8I) had a small impact on the likelihood of responding to the first-line treatment. However, receiving standard first-line treatment increased the likelihood of responding dramatically: vigabatrin (OR $5.2,95 \% \mathrm{CI}$ 2-13.7), prednisolone (OR 8, 95\% Cl 3.1-20.6), and adrenocorticotropic hormone (ACTH; OR I 0.2, 95\% Cl 4.I-25.8).

Significance: First-line treatment with standard therapy was by far the most important variable in determining likelihood of response to treatment of infantile spasms with or without hypsarrhythmia.

KEY WORDS: Epilepsy, Adrenocorticotropic hormone, Vigabatrin, Prednisolone.
West syndrome (WS) is an electroclinical syndrome consisting of epileptic spasms (a seizure type characterized by sudden flexion or extension predominantly of proximal muscles $^{1}$ ) and hypsarrhythmia ${ }^{2}$ on electroencephalography (EEG), and is typically associated with existing or evolving developmental delay. ${ }^{3-5}$ WS has an incidence of $2-4.5$ per 10,000 live births ${ }^{6-10}$ and is associated with numerous etiologies. Infantile spasms is a broader term that can encompass any patient with onset of epileptic spasms during infancy, approximately $75 \%$ of whom have hypsarrhythmia at the time of diagnosis. 9,11

Hypsarrhythmia is the EEG findings of random or chaotic high-amplitude slow waves with intermixed multifocal spikes. ${ }^{5}$ Controversy exists regarding the specific 


\section{Key Points}

- Hypsarrhythmia is not predictive of response to firstline therapy

- Early age at onset of infantile spasms and a history of preexisting epilepsy slightly reduce the likelihood of responding to first-line treatment

- Use of standard first-line medications (ACTH, vigabatrin, prednisolone) have by far the largest impact on the odds of response to first-line treatment outcomes. The primary aim was to determine (1) whether patients without hypsarrhythmia should be treated with medication different from those with hypsarrhythmia and (2) if they have a different likelihood of responding to their first-line treatment. In addition, we evaluated the association between hypsarrhythmia and the following phenotypic features: age (particularly $<3$ months at onset of infantile spasms $^{22}$ ), development, preexisting epilepsy, sex, time interval from onset to diagnosis, and underlying etiology. Finally, we assessed the influence of hypsarrhythmia on treatment choice.

\section{Methods}

amplitudes $(>200 \mu \mathrm{V}$ or $>300 \mu \mathrm{V})$ required and the frequency and distribution of spikes. ${ }^{5,11-15}$ This variability likely accounts, at least in part, for poor interrater reliability when classifying hypsarrhythmia. ${ }^{16}$ Nevertheless, this continues to be considered an important clinical biomarker of a poor prognosis. ${ }^{13,15,17-20}$ Even greater controversy exists regarding specific definitions and utility of modified hypsarrhythmia patterns. ${ }^{15,19}$ Separating hypsarrhythmia from the associated epileptic spasms and the underlying pathology has been challenging. Cohort studies of patients with infantile spasms without hypsarrhythmia suggest that they have varied outcomes and respond to treatments similar to those with hypsarrhythmia. ${ }^{21-24}$ However, patients with and without hypsarrhythmia have never been compared systematically within the same data set.

In 2012 the multicenter Pediatric Epilepsy Research Consortium created the National Infantile Spasms Consortium (NISC) database, which has allowed for a systematic, prospective evaluation of response to various first- and second-line therapies ${ }^{14,25}$ The NISC enrolled patients with infantile spasms with and without hypsarrhythmia, making it a useful database to determine the effect of hypsarrhythmia on response to treatment. In this study, we used the NISC database to evaluate a cohort of patients with infantile spasms without hypsarrhythmia and compare them to those with hypsarrhythmia in terms of phenotypic features and
After written informed consent was obtained from parents or guardians, the patients, who were between 2 months and 2 years with new-onset infantile spasms (defined by the occurrence of epileptic spasms) were enrolled in the NISC multicenter database prospectively as described previously. ${ }^{14,25,26}$ Patients with early infantile epileptic encephalopathy (Ohtahara syndrome) or early myoclonic epilepsy were excluded from the study. Also excluded were patients with incomplete data.

Sex, age at spasm onset, diagnosis, treatment initiation, developmental status prior to spasm onset, prior use of any antiseizure drug (ASD), use of ASDs at the time of diagnosis, and etiology was noted for each patient. Etiology was grouped into seven main categories: genetic/ metabolic, neonatal, neurocutaneous, stroke, structural, and unknown cause with either normal development or abnormal development prior to onset of infantile spasms. Development was determined by treating physicians and was grouped into normal or near normal and clearly abnormal. ${ }^{14}$

There was no specific variable for preexisting epilepsy. Therefore, as a surrogate we utilized whether a patient was already taking an ASD at the time they were diagnosed with infantile spasms. It would be unlikely that infants with clear epilepsy prior to the onset of infantile spasms would have

Accepted October 2, 2017; Early View publication November 3, 2017.

${ }^{1}$ Departments of Pediatrics and Neurology, School of Medicine, University of Colorado Anschutz Medical Campus, Aurora, Colorado, U.S.A.; ${ }^{2}$ Departments of Pediatrics \& Communicable Diseases (Division of Pediatric Neurology), University of Michigan, Ann Arbor, Michigan, U.S.A.; ${ }^{3}$ Center for Neuroscience, Children's National Health System, Washington, District of Columbia, U.S.A.; ${ }^{4}$ Jane and John Justin Neurosciences Department, Cook Children's Hospital, Fort Worth, Texas, U.S.A.; ${ }^{5}$ Departments of Neurology and Pediatrics, Mayo Clinic, Rochester, Minnesota, U.S.A.; ${ }^{6}$ Department of Pediatric Neurology, Mattel Children's Hospital at UCLA, Los Angeles, California, U.S.A.; ${ }^{7}$ Division of Epilepsy and Clinical Neurophysiology, Department of Neurology, Boston Children's Hospital, Boston, Massachusetts, U.S.A.; ${ }^{8}$ Departments of Neurology and Pediatrics, Nationwide Children's Hospital and the Ohio State University College of Medicine, Columbus, Ohio, U.S.A.; ${ }^{9}$ Department of Neurology/Division of Pediatric Neurology, Seattle Children's Hospital University of Washington, Seattle, Washington, U.S.A.; ${ }^{10}$ Department of Neurology, Massachusetts General Hospital/Harvard Medical School, Boston, Massachusetts, U.S.A.; ${ }^{11}$ Departments of Healthcare Policy \& Research and Department of Pediatrics, Weill Cornell Medical Center, New York, New York, U.S.A.; ${ }^{12}$ Division of Child Neurology, Stanford University, Palo Alto, California, U.S.A.; ${ }^{13}$ Division of Neurology, Department of Pediatrics, University of Alabama, Birmingham, Alabama, U.S.A.; ${ }^{14}$ Departments of Neurology and Pediatrics, Johns Hopkins Hospital, Baltimore, Maryland, U.S.A.; ${ }^{15}$ Departments of Pediatrics and Neurology, Division of Child Neurology, Lurie Children's Hospital of Chicago, Northwestern University Feinberg School of Medicine, Chicago, Illinois, U.S.A.; ${ }^{16}$ Departments of Neurology and Pediatrics, Montefiore Medical Center, Albert Einstein College of Medicine, Bronx, New York, U.S.A.; ${ }^{17}$ Departments of Neurology and Pediatrics, NYU School of Medicine, New York, New York, U.S.A.; and ${ }^{18}$ Department of Neurology, Carolinas Healthcare System, Charlotte, North Carolina, U.S.A.

Address correspondence to Scott T. Demarest, Departments of Pediatrics and Neurology, Children's Hospital Colorado, University of Colorado School of Medicine, 13123 East 16th Avenue, B155, Aurora, CO 80045, U.S.A. E-mail: Scott.demarest@childrenscolorado.org

Wiley Periodicals, Inc.

C 2017 International League Against Epilepsy 
been weaned from treatment prior to the onset of infantile spasms. This variable is referred to as preexisting epilepsy for convenience throughout the results.

Hypsarrhythmia was defined as random or chaotic highvoltage $(>200 \mu \mathrm{V})$ slow waves with intermixed multifocal spikes and was determined by the referring epileptologist at each site. Modified hypsarrhythmia was noted in the database but there was no clear definition provided for modified hypsarrhythmia. Modified hypsarrhythmia and hypsarrhythmia were grouped for the purposes of this study given the poor interrater reliability in determining hypsarrhythmia and modified hypsarrhythmia. ${ }^{16}$ Hypsarrhythmia has been defined broadly in this database. ${ }^{5}$

Physicians at each site determined the therapy for each patient based on their own clinical judgment, but standard dosing recommendations were made for adrenocorticotropic hormone $(\mathrm{ACTH})$, oral corticosteroids (prednisolone), and vigabatrin, as described preciously. ${ }^{14}$ These treatments were defined as standard therapies for treatment of infantile spasms. All other treatments were considered nonstandard treatments. Nonstandard treatment includes nine different treatments, with the three most common being levetiracetam, topiramate, and clobazam. Response to therapy was defined as resolution of clinical epileptic spasms and resolution of hypsarrhythmia (if present) within 2 weeks of initiating therapy, without relapse at 3 months after initiation. Patients who had an incomplete response, no response, or relapse were considered nonresponders. ${ }^{14}$ None of the patients enrolled to NISC during this period received combinatorial therapy with more than one standard therapy.

All parents provided written informed consent according to center-specific institutional review boards (IRBs), and the study was approved by the IRBs of all participating institutions. Data used in this study were collected between June 2012 and November 2016.

\section{Statistical analysis}

The associations between hypsarrhythmia at onset of infantile spasms and categorical variables such as sex, preexisting epilepsy, preexisting developmental delay, etiology, and age at onset ( $<3$ months vs. $\geq 3$ months) were assessed using chi-square analysis. Student's $t$-test was used to compare age at onset and time from onset to treatment between the two groups. Response to standard versus nonstandard therapy was assessed independently in those with and without hypsarrhythmia. In addition, a multivariable logistic regression model evaluated the impact of age at onset, preexisting epilepsy, prior development, etiology, and the presence of hypsarrhythmia on first-line treatment choice. Finally, the association between response and firstline treatment was assessed through a multivariable logistic regression model that adjusted for factors that were found to be potential determinants of treatment choice or potentially predictive of response to therapy including the presence of hypsarrhythmia, age at onset of epilepsy, preexisting epilepsy, and choice of drug (ACTH, prednisolone, vigabatrin, or others). The predictors were evaluated for potential collinearity and important interactions. All statistical analysis was performed using SAS version 9.4, and statistical significance was defined as $\mathrm{p}<0.05$.

\section{ReSULTS}

A total of 447 patients were enrolled with infantile spasms; 366 (82\%) with hypsarrhythmia and 81 (18\%) without hypsarrhythmia. All patients without hypsarrhythmia had abnormal EEG backgrounds. Sex, age at onset, time from onset of spasms to diagnosis, presence of moderate or severe preexisting developmental delay, preexisting epilepsy, and etiology were not different in the two groups (Table 1). Although mean age at onset of infantile spasms was the same in the two groups, infants $<3$ months of age at onset of infantile spasms were less likely to have hypsarrhythmia ( 18 of $30,60.0 \%$ ) compared to those $\geq 3$ months (348 of $417,83.5 \%$; $p=0.001)$.

Chi-square and multivariable logistic regression modeling determined that only hypsarrhythmia and preexisting epilepsy were significantly related to prescription of a standard medication as first-line therapy. Infants with hypsarrhythmia were 2.6 times more likely (95\% confidence interval [CI] 1.4-4.7) to be prescribed standard therapy compared with infants who did not have hypsarrhythmia. Patients without preexisting epilepsy were 3.2 times more likely (95\% CI 1.9-5.4) to receive standard first-line therapy compared to patients with previously diagnosed epilepsy (Table 2).

Response to treatment was equivalent in those with and without hypsarrhythmia (Table 1), despite the observation that patients without hypsarrhythmia were less likely to be prescribed standard therapy (72\% vs. $87 \%, \mathrm{p}<0.0004)$. Prescription of standard therapy was independently associated with an increased likelihood of responding to the first therapy, both among patients with hypsarrhythmia $(\mathrm{p}<0.0001)$ and without hypsarrhythmia $(\mathrm{p}<0.0001)$. Of the 81 patients without hypsarrhythmia, 58 patients received one of the standard therapies and 27 patients (47\%) responded. None of the 23 patients without hypsarrhythmia who were prescribed nonstandard therapy responded $(\mathrm{p}<0.0001)$.

Age at onset of infantile spasms and preexisting epilepsy were associated with response to therapy on univariate analysis $(p=0.01$ and $p=0.0007$, respectively). In the multivariable logistic regression, odds of response to therapy increased 1.09 (95\% CI 1.03-1.15) times for each month increase in age at onset of infantile spasms $(p=0.002)$, after adjusting for relevant clinical factors. There was no statistically significant interaction between hypsarrhythmia and age at onset within this model. Patients without a diagnosis of epilepsy at the onset of infantile spasms were 1.7 


\begin{tabular}{|c|c|c|c|}
\hline Characteristic & $\begin{array}{c}\text { Hypsarrhythmia } \\
\mathrm{N}(\%) \text { or mean (SD) }\end{array}$ & $\begin{array}{l}\text { No hypsarrhythmia } \\
N(\%) \text { or mean (SD) }\end{array}$ & $\mathrm{p}$-Value \\
\hline Overall & $366(82)$ & $81(18)$ & \\
\hline Female & $167(46)$ & $35(43)$ & 0.69 \\
\hline Preexisting epilepsy & $104(29)$ & $30(38)$ & 0.13 \\
\hline Moderate or severe developmental delay & $218(60)$ & $47(59)$ & 0.85 \\
\hline Average age at onset (months) & $7.2(4)$ & $6.9(4.7)$ & 0.56 \\
\hline Time from onset of spasms to diagnosis (months) & $0.97(1.9)$ & $0.75(\mathrm{I} . \mathrm{l})$ & 0.17 \\
\hline Onset of spasms at $<3$ months age & $18(5)$ & $12(15)$ & 0.0013 \\
\hline Etiology & & & 0.06 \\
\hline Genetic/metabolic & $68(20)$ & $12(15)$ & \\
\hline Neonatal & $49(14)$ & $14(18)$ & \\
\hline Neurocutaneous & $18(5)$ & $10(13)$ & \\
\hline Stroke & $19(6)$ & $4(5)$ & \\
\hline Structural & $44(13)$ & $16(20)$ & \\
\hline Unknown abnormal development & $78(23)$ & $13(16)$ & \\
\hline Unknown normal development & $68(20)$ & $10(13)$ & \\
\hline \multicolumn{4}{|l|}{ First-line treatment prescribed } \\
\hline Standard & $320(87)$ & $58(72)$ & $0.0004^{a}$ \\
\hline Other treatments & $46(13)$ & $23(28)$ & \\
\hline ACTH & $196(46)$ & $20(25)$ & $0.0002^{b}$ \\
\hline Prednisolone & $85(23)$ & $18(22)$ & \\
\hline Vigabatrin & $66(18)$ & $20(25)$ & \\
\hline Other treatments & $46(13)$ & $23(28)$ & \\
\hline \multicolumn{4}{|l|}{ Response to treatment } \\
\hline \multicolumn{4}{|l|}{ Overall } \\
\hline Responders & $148(40)$ & $27(33)$ & 0.24 \\
\hline Nonresponders & $218(60)$ & $54(67)$ & \\
\hline \multicolumn{4}{|l|}{ Standard treatment } \\
\hline Responder & $142(44)$ & $27(47)$ & 0.76 \\
\hline Nonresponder & $178(56)$ & $31(53)$ & \\
\hline \multicolumn{4}{|l|}{ Other treatments } \\
\hline Responders & $6(13)$ & $0(0)$ & 0.17 \\
\hline Nonresponders & $40(87)$ & $23(100)$ & \\
\hline $\begin{array}{l}\text { Characteristics of patients with and without hypsar } \\
\text { mia) that had that characteristic followed by the perce } \\
{ }^{a} \text { Chi-square test comparing prescribing of standard } \\
{ }^{b} \text { Chi-square test comparing prescribing of ACTH, P }\end{array}$ & $\begin{array}{l}\text { ime of diagnosis. Numb } \\
\text { esis. Bold values indicate } \\
\text { first-line treatment. } \\
\text { abatrin, and other for fir }\end{array}$ & $\begin{array}{l}\text { thin the group (hypsarrh } \\
\text { ficant p-values. }\end{array}$ & ssarrhyth- \\
\hline
\end{tabular}

(95\% CI 1.06-2.81) times more likely to respond to therapy $(\mathrm{p}=0.027$, Table 3$)$.

The presence of hypsarrhythmia did not impact likelihood of treatment response $(\mathrm{p}=0.8)$. Compared to nonstandard treatments, first-line treatment with ACTH, prednisolone, and vigabatrin increased the odds of response by 10.2 (95\% CI 4.1-25.8, p < 0.001), 8 (95\% CI 3.1-20.6, $\mathrm{p}<0.001)$, and 5.2 (95\% CI: 2-13.7, $\mathrm{p}=0.0009)$ times, respectively (Table 3 ).

\section{Discussion}

The results of this study suggest that patients with infantile spasms with or without hypsarrhythmia benefit from the same treatment strategy using one of the first-line medications (ACTH, prednisolone, or vigabatrin). None of the patients without hypsarrhythmia who received nonstandard therapy responded. A prescribing bias was also identified, as patients without hypsarrhythmia or with a history of preexisting epilepsy were less likely to receive standard firstline medications.

The youngest patients ( $<3$ months) were less likely to have hypsarrhythmia at presentation, but patients without hypsarrhythmia were seen at all ages ( 2 months to 2 years). A similar overrepresentation of patients $<3$ months was reported previously in a cohort of patients with infantile spasms without hypsarrhythmia, where 3 of 16 (19\%) were $<3$ months of age at onset. ${ }^{22}$ In our data, there were no other factors that correlated with absence of hypsarrhythmia. Specifically, there was no difference in the time from onset of infantile spasms to diagnosis of infantile spasms based on hypsarrhythmia. This argues against the theory that patients without hypsarrhythmia have been captured earlier and would develop hypsarrhythmia eventually if left untreated. However, a detailed analysis of subsequent EEG studies was beyond the scope of this study. Similarly, there was no 
S. T. Demarest et al.

\begin{tabular}{|c|c|c|c|c|}
\hline \multirow{2}{*}{$\frac{\text { Variable }}{\text { Presence of hypsarrhythmia }}$} & \multirow{2}{*}{$\frac{\text { Odds ratio }}{2.6}$} & \multicolumn{2}{|c|}{$\begin{array}{c}95 \% \text { Wald } \\
\text { confidence limits }\end{array}$} & \multirow{2}{*}{$\frac{p-\text { Value }}{0.0015}$} \\
\hline & & 1.4 & 4.7 & \\
\hline Preexisting epilepsy & 3.2 & 1.9 & 5.4 & $<0.0001$ \\
\hline
\end{tabular}

Table 3. Factors impacting the odds of response to first-line treatment

\begin{tabular}{|c|c|c|c|c|}
\hline \multirow{2}{*}{$\begin{array}{l}\text { Variable } \\
\text { Presence of hypsarrhythmia }\end{array}$} & \multirow{2}{*}{$\frac{\text { Odds ratio }}{0.949}$} & \multicolumn{2}{|c|}{$\begin{array}{c}95 \% \text { Wald } \\
\text { confidence limits }\end{array}$} & \multirow{2}{*}{$\frac{\mathrm{p} \text {-Value }}{0.8556}$} \\
\hline & & 0.54 & 1.669 & \\
\hline Age at onset of infantile spasms & 1.088 & 1.032 & I. 148 & 0.0018 \\
\hline Preexisting epilepsy & 1.728 & 1.063 & 2.809 & 0.0274 \\
\hline ACTH (adrenocorticotropic hormone) vs. nonstandard therapy & 10.247 & 4.078 & 25.751 & $<0.000$ I \\
\hline PRL (prednisolone) vs. nonstandard therapy & 7.981 & 3.092 & 20.601 & $<0.000$ I \\
\hline VGB (vigabatrin) vs. nonstandard therapy & 5.171 & 1.953 & 13.688 & 0.0009 \\
\hline
\end{tabular}

Multivariable logistic regression model evaluating the association between the variables and likelihood of response to first-line therapy. Odds ratio with associated confidence intervals and $\mathrm{p}$-values are provided.

difference in the gross assessment of development of infants at the time of diagnosis of infantile spasms between the two groups.

Etiology was not associated with the presence or absence of hypsarrhythmia. Etiology is possibly the most difficult factor to analyze in studying infantile spasms because there are likely more than 100 unique causes. ${ }^{26,27}$ To analyze data sets based on each individual diagnosis reduces statistical power to the point of being impractical. We grouped patients into seven categories, which cannot capture detailed phenotypic information that may be inherent to a specific etiology. With this caveat in mind the grouping we utilized was not associated with the presence of hypsarrhythmia. The impact of specific etiologies on phenotype and outcomes deserves additional exploration, and the use of large multicenter databases, like NISC, will prove invaluable in this effort as the number of enrolled patients continues to grow.

Ultimately, this study reaffirms that the primary predictor of response to therapy is the use of standard therapy (ACTH, prednisolone, or vigabatrin). Although these treatments were not randomized, they were standardized, and as reported previously, most patients did receive the recommended dose and duration. ${ }^{14}$ NISC is the largest prospective study to date for infantile spasms and clearly demonstrates that earlier age at onset and preexisting epilepsy negatively impact the likelihood of response to therapy, but this impact is modest when compared to treatment choice. After adjustment for treatment bias, hypsarrhythmia is not associated with response to treatment.

The NISC database is limited as a prospective observational study without randomization or long-term follow- up. ${ }^{14,25}$ Although a randomized controlled trial is ideal for determining the optimal treatment, and adjusting for unmeasured confounders, the NISC database allows for adjustment of many confounders and identification of clinical prescribing biases. Additional study is warranted into the long-term implications of hypsarrhythmia on neurodevelopment. However, most evidence available now suggests that each patient has his or her own range of potential outcomes, heavily influenced by their underlying etiology, and that rapid and effective treatment of infantile spasms likely improves a given patient's trajectory within that continuum. $^{28-32}$ Data on long-term developmental outcomes would be a valuable avenue for future research. We supplement use of an ASD at the time of infantile spasms diagnosis for preexisting epilepsy; while these are likely heavily correlated parameters the significance of "preexisting epilepsy" in this paper should be verified with additional studies. Finally, poor interrater reliability between EEG readers when evaluating for hypsarrhythmia remains a potential limitation. ${ }^{16}$ However, as hypsarrhythmia was classified clinically in our multicenter study, our approach and our data are representative of current clinical practice. Therefore, this study suggests that use of hypsarrhythmia as a clinically meaningful predictor of response to therapy for epileptic spasms in children $<2$ years of age is inappropriate.

This analysis demonstrates that patients who receive ACTH, prednisolone, or vigabatrin as first-line treatment have 5-10 times the odds of responding to their initial medication, compared to children who are prescribed nonstandard treatments. Although early age at onset and preexisting epilepsy had some impact on response, first-line treatment with standard therapy was by far the most important 
variable in determining likelihood of response to treatment of infantile spasms regardless of the presence or absence of hypsarrhythmia at the time of diagnosis.

\section{ACKNOWLEDGMENTS}

Funding for this study was received from the American Epilepsy Society and the Pediatric Epilepsy Research Foundation. We would like to give special thanks to Elizabeth Juarez-Colunga, for her assistance with the biostatistical analysis.

\section{Disclosure of Conflicts of INTEREST}

Knupp reports grants from the American Epilepsy Society and Pediatric Epilepsy Research Fund, during the conduct of the study; and grants from Pediatric Epilepsy Research Fund, grants from Zogenix, outside the submitted work. Gaillard reports grants from the Pediatric Epilepsy Research Foundation, during the conduct of the study. Patel reports grants from the Pediatric Epilepsy Research Foundation (PERF), grants from UpsherSmith, grants and personal fees from LivaNova, grants and personal fees from GW Pharmaceuticals, grants from Brain Sentinal, and personal fees from UCB Pharma, personal fees from Supernus, outside the submitted work. Loddenkemper serves on the Laboratory Accreditation Board for Long Term (Epilepsy and Intensive Care Unit) Monitoring, on the Council (and as 2nd Vice President) of the American Clinical Neurophysiology Society, on the American Board of Clinical Neurophysiology, as an Associate Editor for Seizure, and as an Associate Editor for "Wyllie's Treatment of Epilepsy, 6th edition." He is part of pending patent applications to detect and predict seizures and to diagnose epilepsy. He receives research support from the Epilepsy Research Fund, the American Epilepsy Society, the Epilepsy Foundation of America, the Epilepsy Therapy Project, PatientCentered Outcomes Research Institute, the Pediatric Epilepsy Research Foundation, Citizens United for Research in Epilepsy, HHV-6 Foundation, and received research grants from Lundbeck, Eisai, Upsher-Smith, Acorda, and Pfizer. He serves as a consultant for Zogenix, Upsher Smith, and Lundbeck. All other authors have no conflicts of interest to report. We confirm that we have read the Journal's position on issues involved in ethical publication and affirm that this report is consistent with those guidelines.

\section{REFERENCES}

1. Fisher R, Cross H, D'Souza C, et al. Instruction manual for the ILAE 2017 operational classification of seizure types. Epilepsia 2017;58:531-542.

2. Millichap JJ, Millichap JG. Hypsarhythmia or hypsarrhythmia? Pediatr Neurol Briefs 2015;29:64

3. Go CY, Mackay MT, Weiss SK, et al. Evidence-based guideline update: medical treatment of infantile spasms Report of the Guideline Development Subcommittee of the American Academy of Neurology and the Practice Committee of the Child Neurology Society. Neurology 2012;78:1974-1980.

4. Berg AT, Berkovic SF, Brodie MJ, et al. Revised terminology and concepts for organization of seizures and epilepsies: report of the ILAE Commission on Classification and Terminology, 2005-2009. Epilepsia 2010;51:676-685.

5. Lux AL, Osborne JP. A proposal for case definitions and outcome measures in studies of infantile spasms and West syndrome: consensus statement of the West Delphi group. Epilepsia 2004;45:1416-1428.

6. Primec ZR, Kopac S, Neubauer D. Epidemiologic features of infantile spasms in Slovenia. Epilepsia 2002;43:183-187.

7. Riikonen R. Epidemiological data of West syndrome in Finland. Brain Dev 2001;23:539-541.

8. Cowan LD, Hudson LS. The epidemiology and natural history of infantile spasms. J Child Neurol 1991;6:355-364.
9. LúǒAvígsson P, Ólafsson E, Sigurǒardóttir S, et al. Epidemiologic features of infantile spasms in Iceland. Epilepsia 1994;35:802-805.

10. Sidenvall R, Eeg-Olofsson O. Epidemiology of infantile spasms in Sweden. Epilepsia 1995;36:572-574.

11. Karvelas G, Lortie A, Scantlebury MH, et al. A retrospective study on aetiology based outcome of infantile spasms. Seizure 2009;18:197201.

12. Gibbs EL, Fleming MM, Gibbs FA. Diagnosis and prognosis of hypsarhythmia and infantile spasms. Pediatrics 1954;13:66-73.

13. Friedman E, Pampiglione G. Prognostic implications of electroencephalographic findings of hypsarrhythmia in first year of life. $\mathrm{Br}$ Med J 1971;4:323-325.

14. Knupp KG, Coryell J, Nickels KC, et al. Response to treatment in a prospective national infantile spasms cohort. Ann Neurol 2016;79:475-484.

15. Hrachovy R, Frost J, Kellaway P. Hypsarrhythmia: variations on the theme. Epilepsia 1984;25:317-325.

16. Wilmshurst JM, Ibekwe RC, O'Callaghan FJ. Epileptic spasms 175 years on: trying to teach an old dog new tricks. Seizure 2016;44:81-86

17. Wilmshurst JM, Gaillard WD, Vinayan KP, et al. Summary of recommendations for the management of infantile seizures: Task Force Report for the ILAE Commission of Pediatrics. Epilepsia 2015;56:1185-1197.

18. Hrachovy RA, Frost JD. Infantile epileptic encephalopathy with hypsarrhythmia (infantile spasms/West syndrome). J Clin Neurophysiol 2003;20:408-425.

19. Pellock J, Hrachovy R, Shinnar S, et al. Infantile spasms: a U.S. consensus report. Epilepsia 2010;51:2175-2189.

20. Caraballo RH, Fortini S, Reyes G, et al. Epileptic spasms in clusters and associated syndromes other than West syndrome: a study of 48 patients. Epilepsy Res 2016;123:29-35.

21. Caraballo R, Ruggieri V, Gonzalez G, et al. Infantile spams without hypsarrhythmia: a study of 16 cases. Seizure 2011;20:197-202.

22. Marchi LR, Seraphim EA, Corso JT, et al. Epileptic spasms without hypsarrhythmia in infancy and childhood: tonic spasms as a seizure type. Epileptic Disord 2015;17:188-193.

23. Caraballo RH, Fejerman N, Bernardina BD, et al. Epileptic spasms in clusters without hypsarrhythmia in infancy. Epileptic Disord 2003;5:109-113.

24. Knupp KG, Leister E, Coryell J, et al. Response to second treatment after initial failed treatment in a multicenter prospective infantile spasms cohort. Epilepsia 2016;57:1834-1842.

25. Wirrell EC, Shellhaas RAA, Joshi C, et al. How should children with West syndrome be efficiently and accurately investigated? Results from the National Infantile Spasms Consortium. Epilepsia 2015;56:617-625.

26. Hussain SA, Kwong G, Millichap JJ, et al. Hypsarrhythmia assessment exhibits poor interrater reliability: a threat to clinical trial validity. Epilepsia 2015;56:77-81.

27. Osborne J, Lux A, Edwards S, et al. The underlying etiology of infantile spasms (West syndrome): information from the United Kingdom Infantile Spasms Study (UKISS) on contemporary causes and their classification. Epilepsia 2010;51:2168-2174.

28. Eisermann MM, DeLaRaillère A, Dellatolas G, et al. Infantile spasms in Down syndrome-effects of delayed anticonvulsive treatment. Epilepsy Res 2003;55:21-27.

29. Kivity S, Lerman P, Ariel R, et al. Long-term cognitive outcomes of a cohort of children with cryptogenic infantile spasms treated with highdose adrenocorticotropic hormone. Epilepsia 2004;45:255-262.

30. Güveli BTT, Çokar Ö, Dörtcan N, et al. Long-term outcomes in patients with West syndrome: an outpatient clinical study. Seizure 2015;25:68-71.

31. Primec ZR, Stare J, Neubauer D. The risk of lower mental outcome in infantile spasms increases after three weeks of hypsarrhythmia duration. Epilepsia 2006;47:2202-2205.

32. O'Callaghan FJ, Edwards SW, Alber FD, et al. Safety and effectiveness of hormonal treatment versus hormonal treatment with vigabatrin for infantile spasms (ICISS): a randomised, multicentre, open-label trial. Lancet Neurol 2017;16:33-42. 